\title{
UTILIZAÇÃO DE UM ESPECTRÓGRAFO DE PROJEÇÃO COMO UMA FERRAMENTA PARA DEMONSTRAÇÕES SOBRE POLARIZAÇÃO DA LUZ
}

\author{
Eduardo Ribeiro de Azevedo*, Gregório Couto Faria, Tiago Barbin Batalhão, Jae Antonio de Castro Filho, Ercio Santoni, \\ Josimar Luiz Sartori e Luiz Antônio de Oliveira Nunes \\ Instituto de Física de São Carlos, Universidade de São Paulo, CP 369, 13560-970 São Carlos - SP, Brasil
}

Recebido em 17/11/09; aceito em 19/1/10; publicado na web em 12/5/10

\begin{abstract}
PROJECTION SPECTROGRAPH AS A TOOL FOR LIGHT POLARIZATION CLASSROOMS DEMONSTRATIONS. This article describes the use of a projection spectrograph based on an overhead projector for use in classroom demonstrations on light polarization and optical activity. A simple adaptation on a previously developed apparatus allows illustrating several aspects of optical activity, such as circular and linear birefringence, including their wavelength dependence. Specifically, we use the projection spectrograph to demonstrate the optical activity of an aqueous solution of sugar (circular birefringence), of a quartz plate and of an overhead projector transparence film (linear birefringence). A historical survey about the optical activity discovery and the main principles involved is also presented.
\end{abstract}

Keywords: projection spectrograph; optical activity; birefringence.

\section{INTRODUÇÃO}

A propagação da radiação eletromagnética e mais especificamente da luz visível em um meio material depende de características específicas deste meio. Assim, o estudo das modificações sofridas pela luz ao se propagar em um meio traz informações importantes sobre as características atômicas do mesmo. Por exemplo, medindo-se a intensidade de luz absorvida por um material em cada comprimento de onda (espectro de transmissão), pode-se obter informações sobre a sua composição química. No entanto, um feixe luminoso ao atravessar um meio material não sofre somente alteração em suas características espectrais, mas pode também sofrer alteração em seu estado de polarização. Essas alterações são usadas em várias aplicações tecnológicas, por exemplo, o valor comercial da cana-de-açúcar é avaliado com base na sua concentração de sacarose, que é determinada utilizando um método que envolve a avaliação das mudanças na direção da polarização da luz ao atravessar uma solução (polarimetria). Já uma aplicação científica comum que envolve a análise da polarização da luz é a técnica denominada dicroísmo circular que, entre outras aplicações, é utilizada para o estudo da estrutura secundária de proteínas.

Em artigo anterior, foi apresentado um aparato baseado em um retroprojetor com o qual é possível realizar várias demonstrações experimentais envolvendo os processos de emissão e absorção da luz. ${ }^{1}$ Neste artigo, serão apresentadas novas aplicações onde o mesmo aparato é utilizado para demonstrações dos principais conceitos envolvendo polarização da luz. Com o uso do retroprojetor modificado e um acessório proposto é possível analisar a atividade óptica de materiais como função do comprimento de onda, por exemplo, o estudo das propriedades de birrefringência linear e circular dos materiais. Além disso, o uso do retroprojetor com fonte de luz permite que as demonstrações sejam realizadas para um grande número de estudantes.

\section{Histórico das descobertas sobre a polarização da luz}

O primeiro fenômeno relacionado com o que viria a ser chamado de polarização da luz foi relatado em 1669 pelo dinamarquês Erasmo Bartholin, que observou que o cristal de calcita (também conhecido como cristal da Islândia, por ser muito abundante nessa ilha) produ-

\footnotetext{
*e-mail: azevedo@ifsc.usp.br
}

zia duas imagens de um mesmo objeto e, ao rodar o cristal, uma das imagens permanecia fixa enquanto a outra girava ao redor da primeira. Isso ocorre inclusive na incidência perpendicular, quando a lei de Snell (já conhecida na época) prevê que o raio não sofre desvio. $\mathrm{O}$ holandês Christian Huygens fez os raios que atravessavam um cristal de calcita incidirem sobre outro cristal de calcita e percebeu que, ao girar o segundo cristal, havia uma orientação em que era produzida uma única imagem. ${ }^{2} \mathrm{Na}$ época, isso mostrou que a luz que sai de um cristal de calcita não tem as mesmas propriedades que a luz comum.

Duas teorias estavam sendo desenvolvidas na época, por Christian Huygens e Isaac Newton. Huygens explicava as observações com a hipótese de que a velocidade de propagação da luz na calcita depende da direção. Entretanto, isso não era capaz de explicar porque o segundo cristal não produzia também duas imagens. Newton formulou a hipótese de que a partícula de luz tinha "lados", sendo cada uma refratada de maneira diferente dependendo do "lado" da partícula que incide sobre a superfície do cristal de calcita. ${ }^{2}$ A proposta de Newton era que a luz ordinária seria composta por partículas cujos "lados" não têm uma direção preferencial, mas após a passagem pela calcita as partículas em cada raio ficam com seus "lados" orientados (quando isso acontece se diz que a luz é polarizada, e a orientação dos "lados" define o que hoje se conhece como plano de polarização). Com isso, o segundo cristal (se alinhado corretamente) não produz a dupla imagem porque todas as partículas incidem com o mesmo "lado". Isso proporcionava um método de testar se a luz era polarizada (em outras palavras, se os "lados" das partículas que compunham o raio estão ou não alinhados). Essa ideia não está longe do que se entende por correto atualmente.

Os avanços importantes que se seguiram aconteceram no começo do século XIX. Em 1801, Thomas Young, através do experimento da dupla fenda, ${ }^{2}$ consolidou a teoria ondulatória de Huygens. Em 1810, o francês Etienne-Louis Malus descobriu que a luz refletida em uma interface plana entre dois meios poderia ser polarizada, ${ }^{2}$ desde que o ângulo de incidência fosse adequado, e que isso acontecia com praticamente todos os materiais. O ângulo de incidência que produzia luz polarizada foi chamado de ângulo de polarização. Malus mediu o ângulo de polarização para água e vidro (na interface desses meios com o ar).

De acordo com o relato do escocês Sir David Brewster, em seu "Tratado de Óptica", 3 publicado na década de 1830 e que condensava o conhecimento em óptica da época: "No ano de 1810, o grande filósofo francês Malus estava olhando através de um cristal de calcita a luz do 
pôr do sol refletida nas janelas do palácio de Luxemburgo em Paris quando percebeu algo curioso: o raio de luz refletido pelo vidro a um ângulo de $56^{\circ}$ (ou pela água a um ângulo de $52^{\circ} 45^{\prime}$ ) possui as mesmas propriedades que o raio após atravessar um cristal de calcita, isto é, torna-se completamente polarizado, e o plano de polarização é paralelo ao plano de reflexão".

Ele descobriu que isso ocorre com todos os materiais transparentes ou opacos, exceto os metais, mas não conseguiu estabelecer uma relação entre o índice de refração e o ângulo de refração, como comenta Brewster em seu tratado: "Continuando seus experimentos, Malus percebeu que o ângulo de reflexão quando a luz emerge polarizada depende do material de que era constituída a superfície refletora, e após medi-lo em várias interfaces constituídas de diferente materiais (vidro - ar, água - ar), ele concluiu que esse valor não tinha relação com os índices de refração ou com a capacidade de absorção". Neste ponto Malus estava enganado. No ano de 1814, Brewster refez as medidas de Malus e determinou que a tangente do ângulo de reflexão quando a luz emerge polarizada (numa interface entre um material e o ar) é igual à razão entre os índices de refração dos meios que constituem a interface onde ocorre a reflexão, fato que é conhecido como a lei de Brewster (o referido ângulo é conhecido como ângulo de Brewster).

Os experimentos utilizando o cristal de calcita levaram à conclusão de que há uma direção especial no cristal em que um feixe de luz se propaga sem que o seu estado de polarização seja alterado, que foi denominada de eixo óptico. Para descrever a dupla refração, Brewster utilizava os termos ordinário e extraordinário para designar os dois raios: "Quando o plano de polarização de um raio coincidir ou for paralelo à seção principal (plano que contém o eixo óptico e a direção de propagação), o raio é refratado de forma ordinária, ou seja, da mesma forma como ocorre em um material sem as propriedades da calcita, vidro por exemplo; se o plano de polarização for perpendicular à seção principal, será refratado de forma extraordinária".

Em 1810, o francês Augustin Fresnel utilizou os conceitos da teoria ondulatória da luz para explicar os fenômenos de interferência e difração. ${ }^{2}$ Sua proposição mais importante foi considerar a luz como onda transversal. Até então, a luz era tratada como uma onda longitudinal porque o éter (meio no qual se imaginava que preenchia o espaço e permitia a propagação da luz) deveria ter propriedades de um fluido e, portanto, não pode transmitir ondas transversais. Este fato era o que impedia a aceitação da ideia dos "lados", pois em uma onda longitudinal todas as direções perpendiculares à direção de propagação são equivalentes.

Em 1822, Fresnel, utilizando a hipótese de que a luz é uma onda transversal, calculou os coeficientes que governavam a reflexão e refração de um feixe de luz em uma superfície. Os resultados de Fresnel mostraram que os coeficientes dependem da orientação da polarização com relação ao plano de reflexão e previram corretamente que, na incidência sob ângulo de Brewster, a onda com plano de polarização paralelo ao plano de reflexão não é refletida. É importante ressaltar que Fresnel chegou às fórmulas corretas, mesmo sem conhecer completamente a natureza física da luz (luz como onda eletromagnética), que só foi proposta em torno de 1860 pelo inglês James Clerk Maxwell. ${ }^{2}$

Os franceses Jean-Batiste Biot e François Arago incidiram luz linearmente polarizada (produzida por reflexão em ângulo de Brewster) em um cristal de quartzo e analisaram a luz fazendo-a incidir sobre outro bloco de vidro em ângulo de Brewster. ${ }^{2}$ Girando essa placa de vidro (mantendo o ângulo de Brewster), Arago e Biot perceberam cores na imagem, que iam do vermelho ao violeta à medida que a placa era girada. Para alguns cristais, o analisador precisava ser girado para a direita para ir do vermelho ao violeta; para outros, era necessário girar para a esquerda. A conclusão a que eles chegaram é que o cristal de quartzo gira o plano de polarização da luz de uma quantidade que depende da cor (comprimento de onda), o que hoje é conhecido como atividade óptica. O sentido no qual se dá essa rotação depende da orientação do cristal. A Figura 1S, material suplementar, mostra como se dá a rotação do plano de polarização da luz em um cristal de quartzo que gira o plano de polarização para a direita.

\section{A descrição da luz como onda eletromagnética}

Na década de 1860, James Clark Maxwell unificou o conhecimento sobre eletricidade e magnetismo existente na época em um conjunto de equações, que viriam a representar as leis básicas do eletromagnetismo. Combinando esse conjunto de leis de forma consistente, Maxwell previu a existência de ondas que envolviam oscilações de campos elétricos e magnéticos e que poderiam se propagar no espaço livre (vácuo) como ondas transversais, ou seja, os campos elétricos e magnéticos oscilando perpendicularmente à direção de propagação, como mostrado na Figura $2 \mathrm{~S}$, material suplementar. Essas ondas são conhecidas hoje como ondas eletromagnéticas. Ao calcular a velocidade de propagação dessas ondas, Maxwell encontrou um valor muito próximo ao valor da velocidade da luz, já conhecido na época. Motivado por este resultado, Maxwell mostrou que os resultados da óptica poderiam ser explicados assumindo que a luz é uma onda eletromagnética. Tendo isso em vista, percebe-se que não há nenhuma diferença física fundamental entre a luz (visível), as ondas de rádio, o infravermelho ou os raios gama; todos são ondas eletromagnéticas. Assim, as propriedades de polarização da luz, ou de qualquer outra onda eletromagnética, podem ser completamente entendidas utilizando as leis do eletromagnetismo. ${ }^{4}$

As leis do eletromagnetismo são lineares nos campos elétrico e magnético, de modo que o princípio de superposição pode ser usado. Assim, em um meio homogêneo, qualquer raio de luz pode ser descrito como a soma de dois raios linearmente polarizados oscilando em direções perpendiculares com uma diferença de fase constante entre si. ${ }^{4,5}$ Ou seja, o seu campo elétrico pode ser escrito como:

$$
\vec{E}=A \cos \left(\frac{2 \pi n}{\lambda} z-\omega t\right) \hat{x}+B \cos \left(\frac{2 \pi n}{\lambda} z-\omega t+\varphi\right) \hat{y}
$$

onde $n$ é o índice de refração do meio. O estado de polarização da luz depende da razão $A / B$ e da diferença de fase $\varphi$. Se essa diferença de fase for $\varphi=0$ ou $\varphi= \pm \pi$, o fator cosseno pode ser posto em evidência e o campo elétrico resultante aponta sempre na direção do vetor $A \hat{x}$ $\pm B \hat{y}$, ou seja, a onda é linearmente polarizada.

No caso em que a diferença de fase $\varphi$ é igual a $\pi / 2$ é possível mostrar que a direção do campo elétrico gira à medida que a onda se propaga, sendo que neste caso a onda é dita elipticamente polarizada, ou circularmente polarizada quando as amplitudes ao longo das direções x e y são iguais ( $\mathrm{A}=\mathrm{B}$ em 1$)$.

A maioria das fontes luminosas gera luz com polarização aleatória, o que se denomina usualmente de luz não polarizada. No entanto, para facilitar a análise da modificação da polarização da luz ao interagir com um meio é interessante que seja utilizada luz com estado de polarização definido (linear, circular, elíptica). Assim, torna-se necessário produzir luz polarizada a partir de luz não polarizada.

A forma mais simples de se conseguir luz linearmente polarizada é utilizando a reflexão em uma superfície dielétrica (Lei de Brewster). Outro método comum é o método da polarização por absorção. Para entender esse método, imagine um conjunto de fios metálicos posicionados lado a lado, todos na mesma direção, formando uma camada plana. Os elétrons são livres para se mover em cada fio, mas não podem "pular" de um fio para outro. Se um feixe polarizado de ondas eletromagnéticas incide perpendicularmente sobre essa camada com o campo elétrico apontando na direção dos fios, esse feixe põe os elétrons em movimento e isso resulta na sua absorção. Se o campo elétrico for perpendicular aos fios e o comprimento de onda for maior que a distância entre as grades, não há indução de movimento dos 
elétrons e, logo, não há absorção da radiação. Assim, se um feixe não polarizado de ondas eletromagnéticas incidir nessa grade somente a componente cujo campo elétrico é perpendicular à direção das grades atravessará. Esse processo produz luz linearmente polarizada com a metade da intensidade da luz comum incidente. Como um exemplo, observe que os fornos micro-ondas residenciais possuem um reticulado metálico na porta de vidro, cuja função é absorver tanto as componentes horizontais como as verticais da onda gerada no forno, impedindo que haja radiação de micro-ondas emergindo pela janela de vidro.

Para que o mesmo efeito polarizador aconteça para a luz visível, a distância entre as grades condutoras deve ser da ordem de ou menor que $\lambda \approx 500 \mathrm{~nm}$. Obviamente, isso não pode ser obtido com fios metálicos comuns, sendo necessário usar "fios moleculares". Isso pode ser conseguido usando-se moléculas poliméricas com cadeias muito longas e que possam ser alinhadas através do processo de estiramento. Para tornar as moléculas condutoras é utilizado um processo de dopagem com sais especiais. Um exemplo são os conhecidos filmes polaroides, que são constituídos por álcool de polivinila dopado com iodo. O filme polaroide é capaz de polarizar a luz porque absorve uma das componentes da luz não polarizada e permite que a outra o atravesse. Os filmes polaroides podem ser facilmente encontrados em lojas de material fotográfico.

\section{Birrefringência linear: lâminas defasadoras}

Como discutido anteriormente, uma maneira de mudar o estado de polarização da luz é alterando a fase relativa entre as componentes do campo elétrico. Isso pode ser obtido utilizando a propriedade apresentada por alguns materiais conhecida como birrefringência linear. Os materiais que apresentam birrefringência linear possuem dois índices de refração que dependem da sua orientação. Quando um feixe de luz atravessa este tipo de material seu estado de polarização é alterado devido às componentes do campo elétrico que compõem o feixe de luz caminharem com velocidades diferentes em direções distintas no material, por experimentarem índices de refração distintos $(\mathrm{v}=\mathrm{c} / \mathrm{n})$. Entretanto, nesses materiais existe uma direção em que um feixe de luz se propaga sem que o seu estado de polarização seja alterado, ou seja, independentemente da direção de polarização do feixe o índice de refração sentido é o mesmo. Como mencionado anteriormente, essa direção especial é denominada de eixo óptico do material.

Um exemplo de componente óptico cujo funcionamento utiliza o fenômeno de birrefringência linear são as chamadas lâminas defasadoras. Uma lâmina defasadora consiste de um bloco de cristal birrefringente (quartzo, calcita, por exemplo) cortado de modo que o eixo óptico seja paralelo às faces da lâmina. ${ }^{5} \mathrm{Na}$ incidência normal, a direção de propagação é perpendicular ao eixo óptico e, devido à birrefringência do cristal, os índices de refração são distintos para ondas incidindo com polarização paralela e perpendicular ao eixo óptico. Assim, se o feixe incidente for linearmente polarizado, a componente do campo elétrico paralela ao eixo óptico experimentará um índice de refração $n_{o}$ (raio ordinário), enquanto que a componente perpendicular experimentará um índice de refração $n_{e}$ (raio extraordinário).

Seja $z$ a direção de propagação e $x$ a direção do eixo óptico. A onda propagando na lâmina pode ser escrita como:

$$
\vec{E}=A \cos \left(\frac{2 \pi}{\lambda} n_{o} z-\omega t\right) \hat{x}+B \cos \left(\frac{2 \pi}{\lambda} n_{e} z-\omega t\right) \hat{y}
$$

Se a espessura da lâmina for $d$, a diferença de fase entre as duas componentes após o feixe atravessar a lâmina será:

$$
\Delta \varphi=\frac{2 \pi}{\lambda}\left(n_{e}-n_{o}\right) d
$$

Assim, a espessura da lâmina pode ser ajustada para produzir qualquer defasagem que se queira. Se $d$ é tal que $\Delta \varphi= \pm \pi / 2+2 m \pi$ (com $m$ inteiro) a lâmina é chamada de lâmina de quarto de onda. Se incidir luz linearmente polarizada fazendo um ângulo de $45^{\circ}$ com o eixo óptico, as duas componentes do campo elétrico são iguais e a diferença de fase entre as componentes $x$ e $y$ do campo elétrico é $\pi / 2$, ou seja, a onda emergente será circularmente polarizada. Se $\Delta \varphi= \pm \pi$ $+2 m \pi$ (com $m$ inteiro) a lâmina é chamada de lâmina de meia onda. Se a onda incidente for linearmente polarizada, a onda emergente é também linearmente polarizada, mas o plano de polarização é girado por um ângulo $2 \theta$, devido à defasagem de $\pi$ entre as componentes do campo elétrico.

Como pode ser visto pela Equação 4, as lâminas defasadoras, em sua construção mais simples, produzem o efeito para que foram projetadas somente em comprimentos de onda específicos. Por exemplo, a lâmina se comportará como de quarto de onda, meia onda e onda completa (não produz nenhum efeito na polarização da luz ) quando, respectivamente: ${ }^{5}$

$$
\lambda_{m}=\frac{d|\Delta n|}{\left(m+\frac{1}{4}\right)} ; \lambda_{m}=\frac{d|\Delta n|}{\left(m+\frac{1}{2}\right)} ; \lambda_{m}=\frac{d|\Delta n|}{m}
$$

onde $m=0,1,2,3 \ldots$

\section{Birrefringência circular: atividade óptica}

Conforme foi observado por Biot e Arago, algumas substâncias podem girar o plano de polarização da luz. Isso acontece porque os índices de refração dessas substâncias são distintos para luz circularmente polarizada à esquerda ou à direita. De fato, um feixe de luz linearmente polarizado pode ser decomposto em dois feixes de mesma intensidade, sendo um com polarização circular a direita e o outro a esquerda. Assim, dentro do material que apresenta atividade óptica, o índice de refração $n_{+}$para a componente circularmente polarizada a esquerda é diferente do índice $n_{\text {- }}$ para a componente circularmente polarizada a direita e, portanto, as fases dessas duas componentes se tornam distintas à medida que a luz atravessa o meio. A diferença de fase adquirida entre as componentes ao percorrer uma distância $L$ dentro do material é:

$$
\Delta \varphi=\left(n_{+}-n_{-}\right) \frac{2 \pi}{\lambda} L
$$

Esta diferença de fase provoca uma rotação no plano de polarização de um ângulo $\theta$ com relação à direção inicial de polarização, dada por: ${ }^{4,5}$

$$
\theta=-\frac{\Delta \varphi}{2}=-\left(n_{+}-n_{-}\right) \frac{\pi}{\lambda} L
$$

Se $n_{+}<n$, a substância gira o plano de polarização para a direita; diz-se que a substância é destro-rotatória, ou destrógira; caso $n_{+}<n$, a substância é levo-rotatória, ou levógira.

No caso em que a substância opticamente ativa está dissolvida, a atividade óptica também depende da concentração da substância na solução. Neste caso a Equação 6 deve ser reescrita da seguinte maneira: ${ }^{5}$

$$
\frac{\theta}{L}=\alpha(\lambda, T) \cdot \frac{m}{V}
$$

onde $m$ é a massa do soluto, $V$ é o volume da solução e $\alpha$ é uma constante característica do soluto que depende do comprimento de onda $\lambda$ da luz incidente e da temperatura. 


\section{Descrição do aparato}

$\mathrm{O}$ aparato experimental utilizado é baseado em um retroprojetor modificado e já foi apresentado em detalhes na referência 1, estando esquematizado na Figura 3S, material suplementar. Para realização das demonstrações de polarização, foi montado um acessório que consiste basicamente de dois filmes polaroides, um motor elétrico de baixa frequência de rotação $(3 \mathrm{~Hz})$, Figuras $3 \mathrm{~S}$ e 1 (superior), (no nosso caso se utilizou um motor para girar o prato de forno de micro-ondas) e um suporte metálico.

A montagem deste acessório é feita de acordo com o seguinte procedimento: um dos filmes polaroides (polarizador 1) foi cortado em forma de um quadrado de $\sim 15 \mathrm{~cm}$ de aresta, sendo colocado logo acima da fenda de alumínio (com eixo de polarização alinhado ou perpendicular à fenda) para polarizar o feixe de luz que irá incidir sobre o material cuja atividade óptica será analisada. O material a ser analisado é, então, colocado sobre o polarizador 1; o segundo polaroide (polarizador 2) é utilizado para analisar a polarização do feixe que emerge do material. Esse polaroide foi cortado em forma de um círculo com $10 \mathrm{~cm}$ de raio e seu centro acoplado ao eixo do motor elétrico, Figura 1 (superior). Um suporte metálico, colocado em um dos lados do retroprojetor, é utilizado para sustentar o motor a aproximadamente $20 \mathrm{~cm}$ acima da fenda, fazendo com que seja possível girar o polaroide analisador através do acionamento do motor, tal como ilustrado nas Figuras 3S (material suplementar) e 1.

Portanto, com o uso do retroprojetor modificado e o acessório proposto, é possível analisar a atividade óptica do material colocado entre o polarizador e o analisador para cada comprimento de onda da luz incidente, permitindo a análise espectral dos fenômenos de birrefringência linear e circular dos materiais. Os efeitos podem ser visualizados através da projeção com grandes dimensões, própria para demonstrações em sala de aula.

\section{EXPERIMENTOS}

\section{Birrefringência circular: atividade óptica}

Uma demonstração qualitativa da birrefringência circular pode ser feita utilizando uma solução de açúcar em água. A solução de concentração $1 \mathrm{~g} / \mathrm{mL}$ foi colocada em um recipiente cilíndrico de $8 \mathrm{~cm}$ de diâmetro, com uma das bases fechadas por uma janela de vidro, Figura 1 (superior). $\mathrm{O}$ recipiente foi preenchido com a solução até uma altura $\mathrm{H}=10 \mathrm{~cm}$. Os polarizadores 1 e 2 foram inicialmente posicionados com eixos de transmissão alinhados e, em seguida, o cilindro foi colocado entre os mesmos, de modo a cobrir metade da fenda, como mostrado na Figura 1 (superior). Assim, após ser linearmente polarizada pelo polarizador 1, metade do feixe de luz percorre $10 \mathrm{~cm}$ dentro da solução, enquanto que a outra metade atravessa uma camada de ar correspondente. Em seguida, o feixe completo atravessa o polarizador 2 . A fenda foi ajustada para 4 mm de abertura, sendo utilizada uma grade de difração de 600 linhas/ mm e distância do retroprojetor à tela de projeção de 2,8 m. Na Figura 1 (centro) está apresentada a imagem obtida na tela de projeção quando se utilizou a lâmpada de tungstênio do retroprojetor.

Pode-se observar que para a metade do feixe que atravessou a solução a parte azul do espectro é quase totalmente suprimida, indicando que para os comprimentos de onda correspondentes a rotação na polarização imposta pela solução foi próxima de $90^{\circ}$. De fato, a intensidade relativa aumenta do azul para o vermelho, o que mostra qualitativamente que o ângulo de rotação diminui com o aumento do comprimento de onda, conforme previsto pela Equação 6. Para confirmar que o efeito observado se trata de um efeito de rotação de polarização e não de absorção pela solução, o polarizador 2 foi girado de $90^{\circ}$, observando-se predominantemente a luz azul. O efeito de dependência do ângulo de rotação com o comprimento de onda pode também ser observado na Figura 1 (inferior), que apresenta a imagem obtida na tela de projeção quando se utilizou a lâmpada de Hg. Enquanto que na parte superior da Figura 1 (inferior) a decomposição da luz pela grade levou ao aparecimento de três linhas distintas (amarela $-576 \mathrm{~nm}$, verde $-546 \mathrm{~nm}$ e azul $-435 \mathrm{~nm}$ ), na parte superior a linha azul é quase totalmente suprimida, o que mostra novamente a dependência com o comprimento de onda, tal como previsto pela Equação 6. Um aspecto interessante que pode ser notado na Figura 1 (inferior) é que a linha central possui coloração verde ao invés da co-

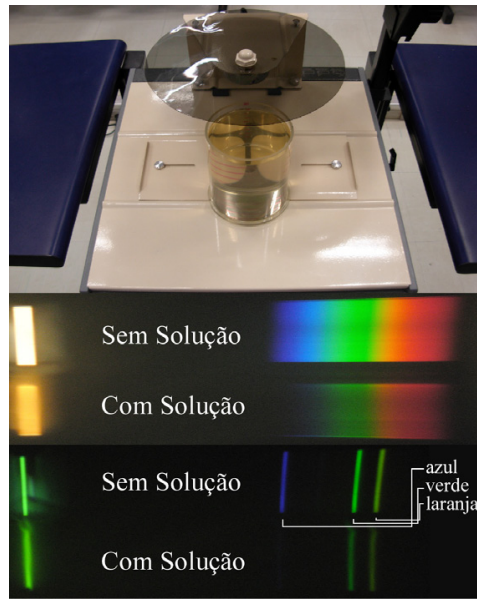

Figura 1. Fotografia da base do retroprojetor na configuração para medida dos ângulos de rotação da polarização induzido pela solução de água e açúcar (superior). Comparação do espectro da luz branca sem atravessar a solução de água e açúcar e após atravessar a solução (centro). Comparação do espectro da luz proveniente de uma lâmpada de mercúrio sem atravessar a solução de água e açúcar e após atravessar a solução (inferior). Somente metade da tela é apresentada, já que a imagem é simétrica em relação ao máximo central
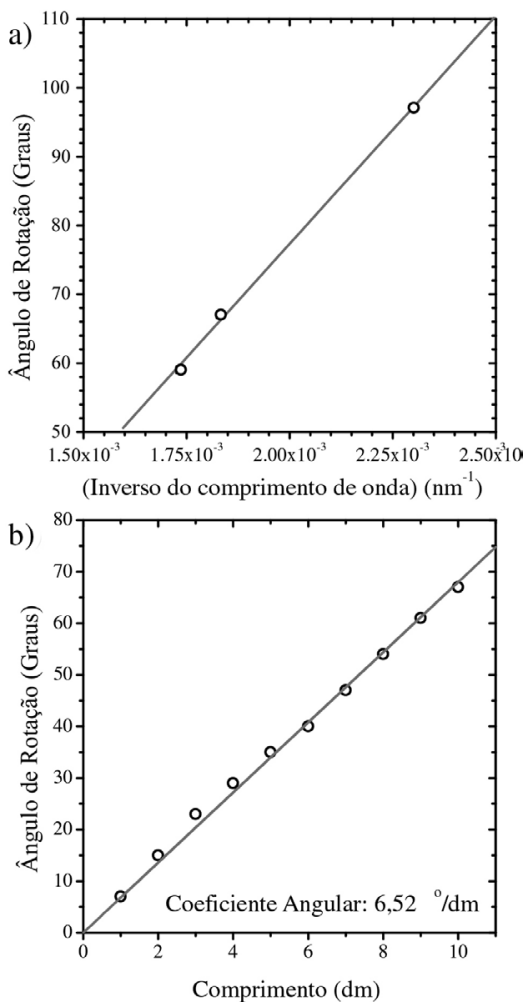

Figura 2. Gráfico do ângulo de rotação da polarização devido à solução de água e açúcar como função do inverso do comprimento de onda (a) e do comprimento (espessura) da camada de solução (b) 
loração "branco azulado" típica da lâmpada de Hg. Este efeito se deve ao fato dos polarizadores não serem totalmente transparentes, sendo sua transparência dependente do comprimento de onda, ou seja, absorvem mais a luz de coloração vermelha.

Além das demonstrações e análises qualitativas descritas acima, é também possível determinar a dependência do ângulo de rotação com o comprimento de onda utilizando as três linhas do $\mathrm{Hg}$ em 576, 546 e $435 \mathrm{~nm}$. Para isso, os polarizadores foram colocados inicialmente com eixos de transmissão perpendiculares (zero de intensidade para todas as linhas) e então o recipiente com a solução foi inserido entre os mesmos, fazendo com que as linhas reaparecessem devido à rotação da polarização da luz. Girou-se então o polarizador 2 até que não se observasse uma determinada linha e anotou-se o ângulo entre o eixo de transmissão do polarizador 2 com e sem a solução inserida. $\mathrm{O}$ comprimento de onda correspondente a cada linha foi determinado conforme o procedimento descrito na referência 1. Na Figura 2a está mostrado um gráfico do ângulo de rotação da polarização $\theta$ como função do inverso do comprimento de onda $1 / \lambda$. Os três pontos experimentais correspondem às três linhas do $\mathrm{Hg}$. Assim, a relação linear obtida mostra uma dependência de $\theta$ com o inverso do comprimento de onda em concordância com a previsão da Equação 6.

Para demonstrar a dependência do ângulo de rotação da polarização com o comprimento da camada de água e açúcar utilizou-se também a solução de concentração $1 \mathrm{~g} / \mathrm{mL}$. Neste caso, a altura (espessura) da camada $\mathrm{H}$ foi variada de $1 \mathrm{a} 10 \mathrm{~cm}$, sendo o ângulo de rotação da polarização determinado como função do comprimento da camada de solução percorrida pelo líquido para a linha amarela do $\mathrm{Hg}$. Os resultados estão mostrados na Figura 2b, que ilustra o gráfico do ângulo de rotação como função da espessura da camada de solução. A relação linear entre o ângulo de rotação e o comprimento, prevista pelas Equações 6 e 7, pode ser prontamente verificada. De fato, o coeficiente angular da reta obtida é o produto da constante $\alpha(\lambda, T)$ pela concentração da solução, Equação 7. Assim, como a concentração da solução é conhecida, é possível utilizar o gráfico da Figura $2 \mathrm{~b}$ para determinar a constante $\alpha(\lambda, T)$ para $\lambda=576 \mathrm{~nm}$ (linha amarela do mercúrio) e $T=27^{\circ} \mathrm{C}$ (temperatura da sala). $\mathrm{O}$ valor obtido foi de $\alpha=(65,2 \pm 0.1)\left({ }^{\circ} \mathrm{mL}\right) /(\mathrm{DM} \mathrm{g})$. Este valor é muito próximo do valor de referência para a sacarose utilizando a linha amarela do sódio, $\alpha=66,4\left({ }^{\circ} \mathrm{mL}\right) /(\mathrm{dm} \mathrm{g})$ para $\lambda=589 \mathrm{~nm} .^{6}$

\section{Birrefringência linear}

A seguir serão descritos alguns procedimentos que demonstram o uso do aparato em demonstrações de birrefringência linear. Para validar o método será utilizada uma lâmina defasadora comercial e, em seguida, a birrefringência induzida por uma folha de transparência para retroprojetor será demonstrada. Em ambos os casos, os materiais birrefringentes foram colocados entre os dois polarizadores do aparato e utilizou-se uma grade de difração de 600 linhas $/ \mathrm{mm}$. Na Figura 3, está mostrada uma fotografia das montagens utilizadas.

\section{Birrefringência linear de uma lâmina defasadora de quartzo}

Geralmente a lâmina defasadora é especificada pelo seu tipo e pelo comprimento de onda em que desempenha a função para que é designada (quarto de onda, meia onda). De fato, as lâminas defasadoras mais comuns (lâminas de múltiplas ordens) funcionam com o fim especificado para vários comprimentos de onda dados pela Equação 4. Neste caso, as lâminas defasadoras são simplesmente placas de espessura milimétrica feitas com cristais birrefringentes, sendo o quartzo o mais utilizado.

Para demonstrar as propriedades birrefringentes das lâminas defasadoras, utilizou-se o aparato apresentado com a lâmpada de

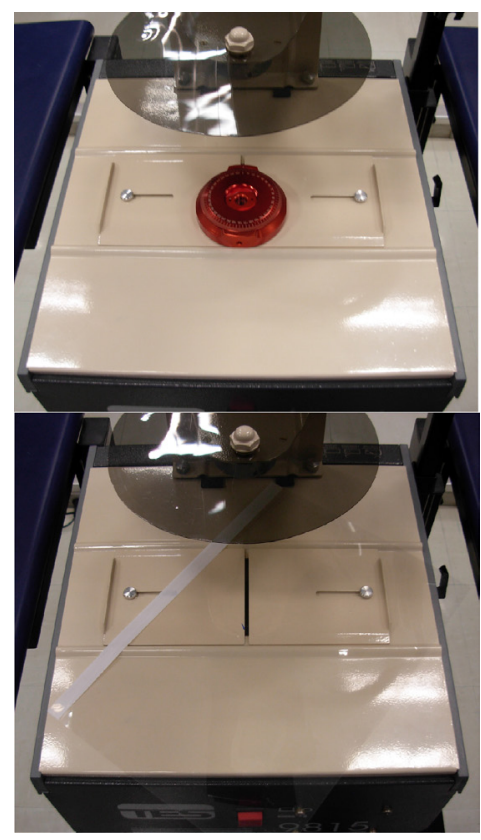

Figura 3. Fotografia da base do retroprojetor configurado para as demonstrações de birrefringência linear em uma lâmina de quartzo com suporte goniométrico (superior) e em um filme de transparência para retroprojetor (inferior)

tungstênio e uma lâmina defasadora de quartzo de 0,470 \pm 0,005 $\mathrm{mm}$ de espessura (medida com um micrômetro). Neste caso, a lâmina deve ser colocada de modo que o seu eixo óptico fique a $45^{\circ}$ do eixo de transmissão do polarizador 1 , o que foi ajustado utilizando um goniômetro, tal como mostrado na Figura 3 (superior). A montagem experimental é idêntica à mostrada na referência 7 , somente diferindo pelo uso do retroprojetor como espectrógrafo.

Consideram-se inicialmente duas situações particulares, sendo que na primeira os polarizadores estão com eixos de transmissão alinhados e na segunda os polarizadores estão com eixos de transmissão perpendiculares. Para os comprimentos de onda em que a lâmina funciona como uma lâmina de meia onda, a polarização da luz (definida pelo polarizador 1) é girada de $90^{\circ}$. Nesta situação, quando os dois polarizadores estiverem alinhados aparecerão regiões escuras no padrão projetado. Isto pode ser visualizado na Figura 4 (superior), que ilustra o padrão projetado na tela quando foi colocada uma lâmina defasadora em parte da região entre os polarizadores (com eixos de transmissão alinhados). Na parte de cima do padrão a luz não atravessa a lâmina defasadora e por isso se observa o padrão espectral da luz branca. Note que é possível perceber que a separação entre duas raias escuras é maior para comprimentos de onda maiores, o que está de acordo com a dependência de $\lambda$ com o inverso de $m$, conforme previsto pela Equação 4 .

Em uma segunda situação, os polarizadores são colocados com eixos de transmissão perpendiculares entre si. Neste caso, o padrão projetado da luz que atravessa a lâmina apresentará regiões escuras toda vez que não houver rotação da polarização, ou seja, quando a lâmina funcionar como lâmina de onda completa. Note ainda que as regiões que apareciam escuras com os polarizadores alinhados (lâmina funcionando como lâmina de meia onda) agora aparecem claras. Na Figura 4 (inferior) está mostrado o padrão obtido para a situação em que os polarizadores foram posicionados com eixos de transmissão perpendiculares. Observe que a região onde a luz que não atravessou a lâmina defasadora aparece escura (polarizadores perpendiculares). Já o padrão com raias escuras é claramente observado na parte inferior da figura.

Considerando que $m_{\mathrm{o}}$ seja o menor valor de $m$ correspondente a um comprimento de onda que pode ser observado a olho nu, de acordo 


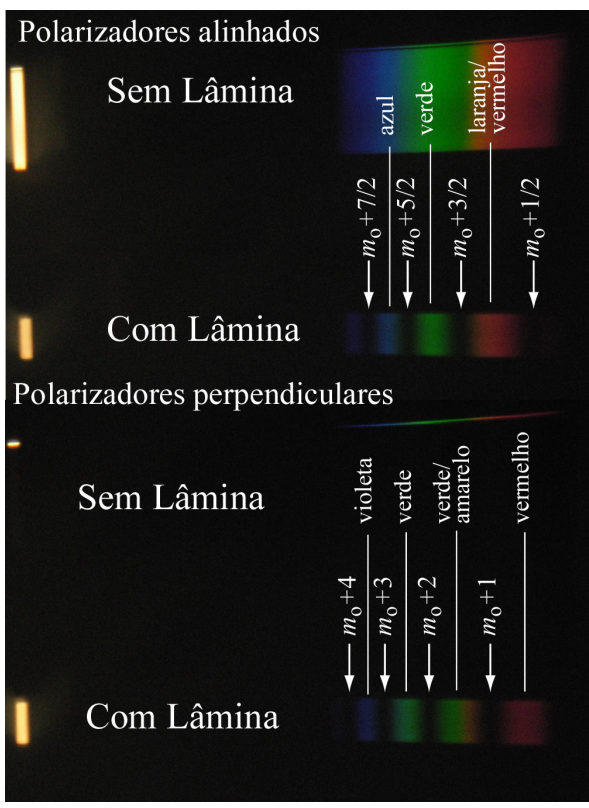

Figura 4. Fotografia da projeção na tela do padrão obtido nas demonstrações de birrefringência linear com uma lâmina defasadora de quartzo com os polarizadores alinhados (superior) e com os polarizadores cruzados (inferior)

com a Equação 5, pode-se concluir que para um mesmo valor de $m_{\mathrm{o}}$ o comprimento de onda correspondente à lâmina funcionando como meia onda deve ser menor que para a lâmina como onda completa, o que justifica a indexação de acordo com $m_{\mathrm{o}}$, tal como mostrada na Figura 4. De fato, os comprimentos de onda correspondentes às raias escuras, em ambos os casos mostrados na Figura 4, podem ser previsto de maneira geral utilizando a seguinte expressão:

$$
\lambda_{m_{o}}(m)=\frac{d|\Delta n|}{\left(m_{\mathrm{o}}+m\right)}
$$

onde $m=0,1 / 2,1,3 / 2,2,5 / 2,3,7 / 2 \ldots$, sendo que para $m$ inteiro a lâmina funciona como onda completa e para $m$ semi-inteiro ela funciona com lâmina de meia onda. Essa expressão pode ser verificada quantitativamente usando os valores dos índices de refração ordinário e extraordinário para o cristal de quartzo no comprimento de onda especificado. ${ }^{8}$

Um efeito visual interessante pode ser obtido utilizando o motor para girar o polarizador 2. Neste caso, haverá um intercâmbio dinâmico entre as duas situações anteriores (polarizadores cruzados e alinhados), e o que se observa é uma animação onde as raias escuras desaparecem de uma posição e aparecem em outra, correspondendo às situações onde as lâminas funcionam como lâmina de meia onda e lâmina completa.

\section{Birrefringência linear de um filme de transparência}

As análises anteriores foram realizadas com o objetivo de demonstrar a possibilidade de se obter informações quantitativas sobre os materiais birrefringentes. Por isso, utilizou-se uma lâmina comercial de características conhecidas. No entanto, embora disponíveis comercialmente, é importante mostrar que os mesmos experimentos podem ser realizados utilizando materiais de fácil acesso. Neste sentido, já foi mostrado que transparências para retroprojetores apresentam birrefringência e podem ser utilizadas como lâminas defasadoras. ${ }^{7,9}$ Isto se dá porque no processo de fabricação são utilizados processos de fusão e estiramento de material plástico, o que produz anisotropia estrutural que causa a birrefringência óptica.

Para demonstrar a birrefringência, utilizou-se uma transparência de espessura $0,075 \pm 0,05 \mathrm{~mm}$. Neste caso, o eixo óptico do filme não é conhecido, mas se pode utilizar o próprio aparato para determinálo. Como discutido anteriormente, uma lâmina defasadora de meia onda provoca uma rotação de um ângulo $2 \theta$ na polarização da luz toda vez que a direção de polarização da luz incidente formar um ângulo $\theta$ com o eixo óptico da lâmina. Assim, se colocarmos os eixos de transmissão dos dois polarizadores alinhados e inserirmos a transparência entre eles, as raias escuras decorrentes da rotação da polarização por $90^{\circ}$ só aparecerão quando o eixo óptico da transparência formar $45^{\circ} \mathrm{com}$ o eixo de transmissão dos polarizadores. Deste modo, é possível determinar o eixo óptico da transparência girando-a entre os polarizadores até que as raias escuras fiquem bem definidas.

Na Figura 5 está mostrada a projeção na tela quando o eixo óptico do filme de transparência está $0^{\circ}$ ou a $45^{\circ}$ do eixo de transmissão dos polarizadores. Como discutido, as raias escuras desaparecem completamente quando o eixo óptico está alinhado com os polarizadores e são evidenciados quando ele está a $45^{\circ}$ (situação a).

a)
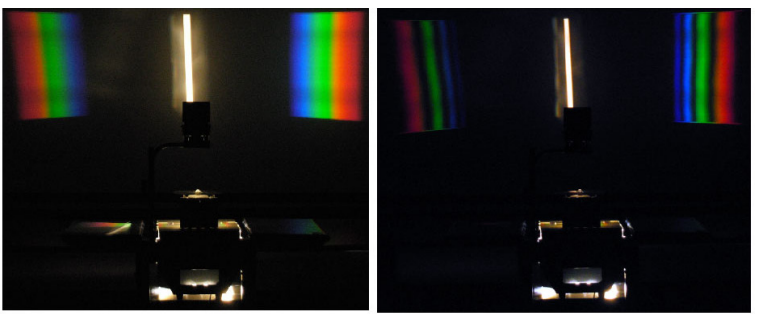

b)
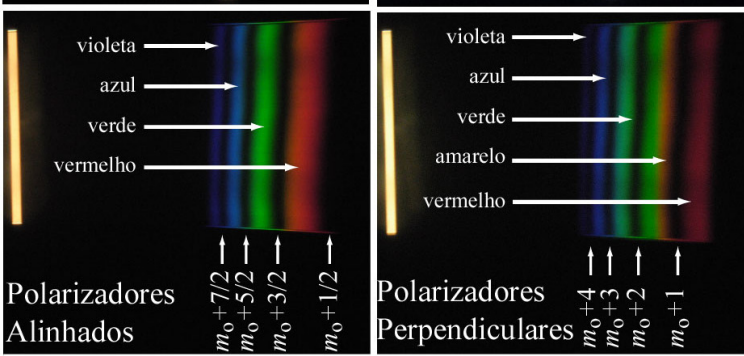

Figura 5. Fotografia da projeção na tela do padrão obtido nas demonstrações de birrefringência linear com um filme de transparência de retroprojetor. a) Com o eixo óptico alinhado (esquerda) e a $45^{\circ}$ (direita) do eixo dos polarizadores. b) Com os polarizadores alinhados (esquerda) e cruzados (direita)

\section{CONCLUSÃO}

Neste artigo foi descrito o uso de um retroprojetor para demonstrações sobre polarização da luz. O uso do retroprojetor modificado e do acessório adaptado permitiu analisar qualitativa e quantitativamente a atividade óptica de materiais, inclusive a dependência com o comprimento de onda. Especificamente, foram apresentadas maneiras de se demonstrar a birrefringência circular em uma solução concentrada de água e açúcar, bem como a dependência do fenômeno com o caminho óptico e comprimento de onda. Foram também apresentados procedimentos para se realizar demonstração e quantificação do fenômeno de birrefringência linear em uma lâmina de quartzo e em uma transparência para retroprojetor. O uso do retroprojetor com fonte de luz permite que as demonstrações experimentais sejam realizadas em classes com grande número de estudantes, inclusive com quantificação dos resultados.

\section{MATERIAL SUPLEMENTAR}

No material suplementar estão apresentadas três figuras citadas no texto, ilustrando o desvio da luz ao passar por um meio oticamente ativo, a propagação de uma onda eletromagnética linearmente polarizada e o esquema do retroprojetor modificado. Está disponível 
em http://quimicanova.sbq.org.br na forma de arquivo .PDF, com acesso livre.

\section{AGRADECIMENTOS}

Ao técnico C. A. Pereira pelo apoio técnico na construção e adaptação do retroprojetor.

\section{REFERÊNCIAS}

1. de Azevedo, E. R.; Nunes, L. A. O.; Quim. Nova 2008, 31, 2199.
2. Cropper, W. H.; Great Physicists; $1^{\text {st }}$ ed., Oxford University Press: Oxford, 2001.

3. Brewster, D.; A Treatise on Optics, Longman: London, 1831.

4. Tipler, P.; Física - Eletricidade e Magnetismo, Ótica, $4^{\mathrm{a}}$ ed., Livros Técnicos e Científicos: Rio de Janeiro, 2000.

5. Hecht, E.; Zajac, A.; Optics, Addison-Wesley: New York, 1974.

6. Carlin, N.; Szanto, E. N.; Seale, W. A.; Jorge, F. O.; Souza, F. A.; Bechtold, I. H.; Gasques, L. R.; Rev. Bras. Ens. Fis 2005, 27, 349.

7. Medhat, M.; El-Zaiat, S. Y.; Opt. Commun. 1997, 141, 145.

8. Sosman, R. B.; The Properties of Silica, Tudor: New York, 1927.

9. Savukov, Y.; Budker, D.; Appl. Opt. 2007, 46, 5129. 


\section{UTILIZAÇÃO DE UM ESPECTRÓGRAFO DE PROJEÇÃO COMO UMA FERRAMENTA PARA DEMONSTRAÇÕES SOBRE POLARIZAÇÃO DA LUZ}

Eduardo Ribeiro de Azevedo*, Gregório Couto Faria, Tiago Barbin Batalhão, Jae Antonio de Castro Filho, Ercio Santoni, Josimar Luiz Sartori e Luiz Antônio de Oliveira Nunes

Instituto de Física de São Carlos, Universidade de São Paulo, CP 369, 13560-970 São Carlos - SP, Brasil

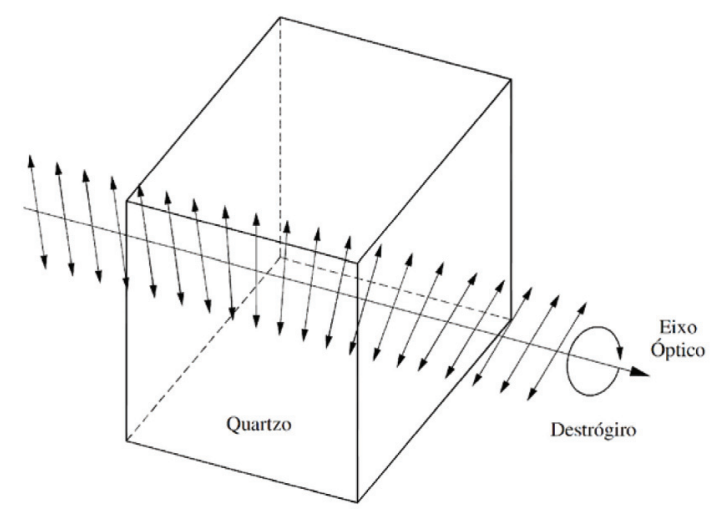

Figura 1S. Representação gráfica da mudança na direção de polarização da luz provocada por um cristal destrógiro

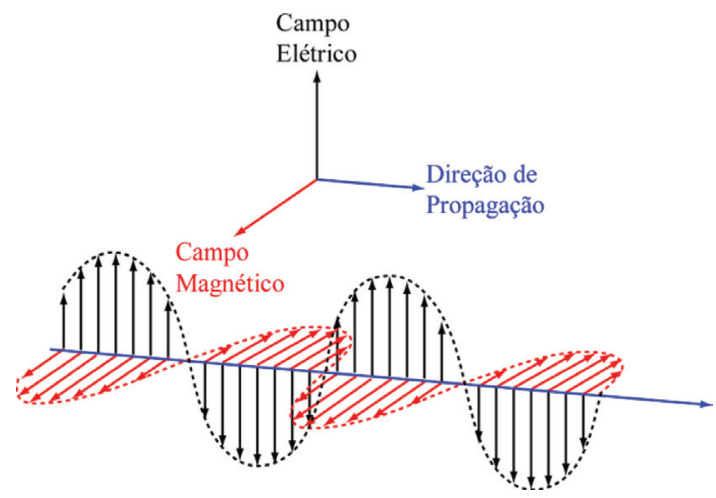

Figura 2S. Representação gráfica dos campos elétrico e magnético de uma onda linearmente polarizada

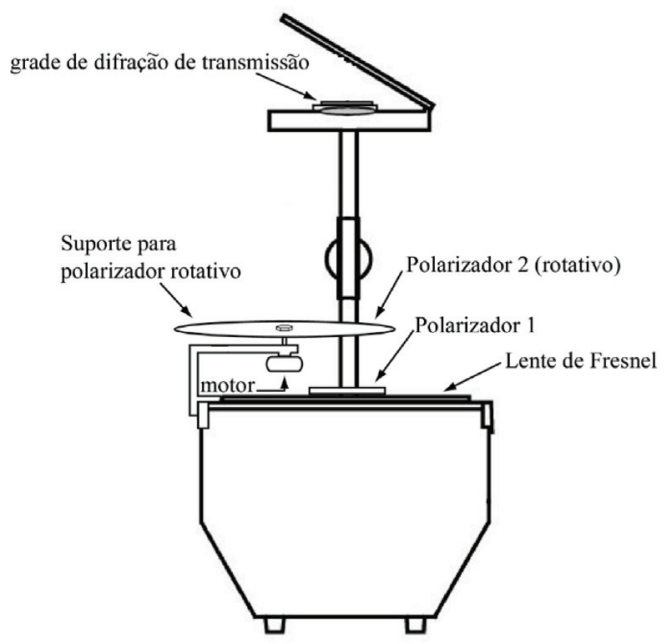

Figura 3S. Desenho esquemático do retroprojetor com as adaptações propostas

*e-mail: azevedo@ifsc.usp.br 